\title{
Electrification, Power Outages and Employment
}

\author{
Josephine Ofori Adofo ${ }^{1}$ \\ ${ }^{1}$ University of Hawaii at Manoa, Honolulu, HI 96822, Unites States \\ Correspondence: Josephine Ofori Adofo, University of Hawaii at Manoa, Honolulu, HI 96822, Unites States
}

Received: May 14, 2020

Accepted: June 19, 2020

Available online: June 29, 2020

doi:10.11114/aef.v7i4.4919

URL: https://doi.org/10.11114/aef.v7i4.4919

\begin{abstract}
Although electrification rates have increased in developing countries, the poor quality of electricity still remains a challenge. This paper studies the effects of electrification at the intensive margin, using a fixed effects approach. I find that power outages significantly reduce employment, earnings, and hours of work. A key channel through which outages affect employment is decreased prevalence of small and medium enterprises (SMEs) among households. Evidence indicates that severe outages reduce opportunities for households to indulge in income generating activities. The decrease in employment opportunities is further exacerbated by reduced industrial growth and changes in the industrial composition. The results suggest that unreliable electricity may have a negative implication for job creation in developing countries.
\end{abstract}

Keywords: employment, electricity shortages, infrastructure, firms, electrification, households

\section{Introduction}

Despite the rapid expansion in electricity infrastructure over the past decades, only 42.8 percent of Sub-Sahara Africa's population has access to electricity (World Bank, 2018). In countries where majority of the population have access to electricity, power outages are frequent, thus raising questions about quality. Theory predicts that access to electricity creates opportunities for households when they adopt this new technology. Because less time is needed for home production, thereby freeing up time for households to supply their labor to markets (Gronau, 1977).

Furthermore, electricity infrastructure presents opportunities for entrepreneurs to create new firms and for existing firms to expand. As firms expand and new ones emerge, employment opportunities increase. Evidence shows that at the extensive margin, electricity promotes industrial growth and increases households' labor supply (Dinkelman, 2011; Rud, 2012). Even though the impacts of electrification have been well documented in the literature, ${ }^{1}$ little is known about the impacts of unreliable electricity supply. The quality of electricity is crucial because the direction of the effect ultimately depends on whether the available electricity is of low or high quality. For instance, macro level evidence indicates that frequent electricity shortages have a substantial negative effect on economic growth (Andersen \& Dalgaard, 2013).

At the micro level, a few influential studies find that electricity shortages affect firm revenue and productivity negatively, and increase firms' cost of production (Alam, 2013; Cole, Elliott, Occhiali, \& Strobl, 2018; Collard-Wexler \& O'Connell, 2016; Fisher-Vanden, Mansur, \& Wang, 2015). Fisher-Vanden et al. (2015) find that firms respond to outages by outsourcing and substituting other inputs for energy. Previous work has mainly focused on the effects of power outages on large manufacturing firms. Less is known about the impacts on small and medium firms (SMEs). ${ }^{2}$ The World Bank enterprise survey indicates that 79.1 percent of SMEs in Sub-Saharan Africa experienced electricity outages and 40.1 percent cited electricity outage as a constraint to operating a business. ${ }^{3}$ In Ghana, these numbers are particularly high. 89.1 percent of businesses experienced outages and 61.2 percent cited electricity outage as a constraint to operating a business. Between 1997 and 2013, Ghana experienced three severe energy crises that led to frequent electricity shortages and power rationing.

\footnotetext{
${ }^{1}$ See for example Morimoto and Hope (2004), Kanagawa and Nakata (2008), Peters and Vance (2011), Grogan and Sadanand (2013)

${ }^{2}$ Few papers that focus on small and medium firms include Alby, Dethier, and Straub (2013), Abeberese, Ackah, and Asuming (2017), Hardy and Mccasland (2019)

${ }^{3}$ World Bank Enterprise Survey, Enterprise Surveys (http://www.enterprisesurveys.org).
} 
In this paper, I examine the effects of unreliable electricity supply on labor market outcomes specifically in SMEs in Ghana. I focus on SMEs for two reasons. First, less is known about how severe outages affect these firms. Secondly, a large percentage of firms in Ghana are informal, small and medium in nature. To examine the impacts of unreliable electricity supply, I use the variability in nighttime lights from satellite imagery as a measure of power outage, following a procedure developed by Alam (2013). I find that outages reduce employment, hours of work and earnings. A 10 percent increase in outages reduce employment by 0.52 percentage points ( 7.5 percent) and monthly earnings by 3.4 percent.

To understand the factors that drive these impacts, I investigate a number of potential mechanisms. I first examine the effect of power outages on firm outcomes. The results suggest that outages significantly reduce industrial output and the total number of firms. Moreover, outages affect the composition of industry negatively, which is measured as the number of electricity-intensive firms. Unreliable electricity supply discourages entrepreneurs from investing in highly productive electricity-intensive industries, and cause exiting firms to operate less electricity-intensive production processes. Additionally, I find that in response to severe outages, firms decrease wages and the number of workers they employ as labor productivity decreases. ${ }^{4}$

Next, I look at the impacts of outages on the prevalence of SMEs. The results show that power outages reduce the probability of enterprise ownership among households. Most households engage in income generating activities in small and medium enterprises (SMEs). Outages affect the creation of new SMEs because of the high cost of operation. The advent of frequent power outages implies that businesses have to rely on generators to ensure smooth operation. However, majority of the individuals who establish SMEs do not have the capacity to invest in alternative energy sources.

The paper makes important contributions to the literature. First, it contributes to a small strand of literature that looks at electricity shortages and firm outcomes. In contrast to recent work that studies large manufacturing firms, I focus on small and medium firms. SMEs are crucial for job creation in developing countries. Secondly, it provides evidence on how unreliable electricity affects the prevalence of SMEs among households, which previous studies have not considered. At the extensive margin, literature on electrification argues that access to electricity creates employment avenues for households, increase labor supply, earnings, and hours of work. ${ }^{5}$ My results indicate that electricity shortages affect earnings and employment opportunities available to households. Closely related to this study is a paper by Chakravorty, Pelli, and Ural Marchand (2014). Lastly, the paper contributes to the discussion on infrastructure provision by highlighting the importance of quality (Baisa, Davis, Salant, \& Wilcox, 2010; Donaldson, 2018).

The rest of the paper is organized as follows. Section 2 describes the electricity sector in Ghana. Section 3 describes the data, Section 4 outlines the empirical strategy, and Section 5 discusses the main results. Section 6 concludes.

\section{Electricity Sector in Ghana}

Electricity generation, transmission, and distribution are controlled by separate entities in Ghana. The Volta River Authority (VRA), Bui Power Authority, and Independent power Producers (IPPs) are responsible for power generation. ${ }^{6}$ Hydro electricity generation accounts for 50\% of the country's electricity and the remaining $50 \%$ are from thermal and solar sources. Prior to deregulations and reforms in the energy sector, Ghana's energy sector was solely state-owned. The deregulation paved a way for Independent Power Operators (IPPs) to enter the energy market. However, the state corporations control a greater percentage of the generation capacity. The Ghana Grid Company Limited (GRIDCo) is responsible for transmitting electricity to the distribution companies. The distribution companies, Electricity Company of Ghana (ECG) and Northern Electricity Distribution Company (NEDCo), are responsible for supplying electricity to customers. ECG serves customers in the southern part of Ghana whereas NEDCo serves those in the Northern part.

Electricity shortages occur frequently in Ghana. Energy crisis in Ghana dates back to between 1982 and 1984 when the country experienced its first power crisis. Other power crises include the 1998-2000 crisis, 2006-2007 crisis, and the most recent 2012-2013 crisis. The first episode of energy crisis was mainly due to a drought, which made hydroelectricity generation impossible. The two other episodes were also as a result of low water levels of the two major electricity-generating dams. Since half of the country's power is generated from hydro plants, any threat to the constant flow of water posses serious risks to the supply of power. As a remedy for the crisis, the government of Ghana invested in other sources of energy such as thermal and solar to ensure adequate electricity supply. The 2012-2013 crisis

\footnotetext{
${ }^{4}$ Some firms may adjust working hours, or shut down to minimize cost in response to severe power outages. This is common among SMEs in developing countries.

${ }^{5}$ See, for example Peters and Vance (2011), Dinkelman (2011), Lipscomb (2013), Grimm, Sparrow, and Tasciotti (2015), Barron and Torero (2017), van de Walle, Ravallion, Mendiratta, and Koolwal (2017), Grogan (2018)

${ }^{6}$ The Volta River Authority (VRA) and Bui Power Authority are government-owned organizations.
} 
was the longest and most severe power crisis as it lasted from late 2012 to 2015 . Outages were unplanned and power lost for several hours. As a result, the electricity Company of Ghana introduced a loading shedding schedule where businesses and households enjoy electricity for 12 hours and loose power for 24 hours. Besides the power rationing, there were frequent power cuts due to system maintenance problems, which were not communicated to the public beforehand.

Some of the major reasons for shortages in Ghana are transmission losses, distribution, commercial and technical losses. In 2003, Ghana lost a total of about 59\% of electricity generated in distribution losses and 5.9\% in transmission losses .? Figure 1 shows the transmission and distribution loss between the years 2000 and 2015. The transmission and distribution agencies often cite system failures and system maintenance as the reasons for power outage. Part of the commercial losses is due to defective meters whereas limited transmission capacity causes technical losses. This shows the lack of investment in quality infrastructure in the sector. Additionally, because the price of electricity is low, the distribution companies are unable to generate enough revenue to cover the cost of supply.

Due to the frequent nature of outages in Ghana, firms and households resort to other energy sources. Severe outages cause firms and households to switch to alternative coping mechanisms. Available alternatives include generators, lamps, lanterns, and battery powered appliances. Most firms produce their own electricity by buying or renting a generator. The use of generators can be costly for both households and SMEs. As a result, majority of these firms change their production processes to less electricity-intensive ones and operate at different times of the day when electricity is available. Some households as well postpone certain activities that require the use of electricity to times when electricity is available.

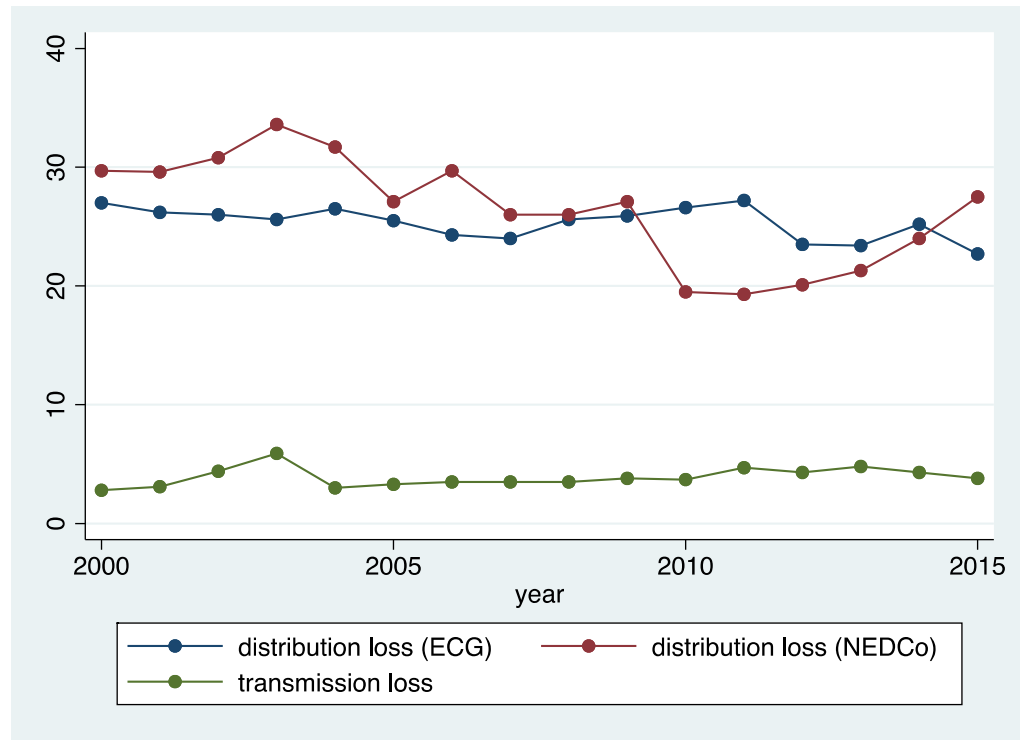

Figure 1. Transmission and Distribution Losses

Notes: Transmission loss is a percentage of net electricity generation. Distribution loss includes both commercial and technical losses. The Electricity Company of Ghana (ECG) compiles this data.

\section{Data}

\subsection{Labor Market Outcomes}

The main source of data for the employment effects of power outages is the Ghana Living Standards Survey (GLSS), a repeated cross section survey. I construct a panel data set of district aggregate variables covering the years 2005 to 2013 , together with district level information on population, population per square kilometers, poverty rate, average monthly rainfall and infrastructure. The population data comes from the Ghana Statistical Service population census and covers the periods 2000 and 2010. The rainfall data includes average monthly precipitation for each district in Ghana.

\footnotetext{
${ }^{7}$ The total distribution loss includes 25.6 percent loss from ECG and 33.6 percent from NEDCo. Stakeholders and policy makers are hopefull that the discovery of oil in Ghana will help resolve part of the country's electricity shortages problem. Readers interested in oil discvory in Ghana can refer to Ofori Adofo, Tarui, and Tanaka (2019).
} 
The employment variables are created from the employment section of the household survey. The employment section contains information on individuals who report working in the past week or year, monthly earnings from paid work and self-employment, and the sector of employment. Additional variables from the household survey include gender, age and ethnicity. Three main variables are used as labor market indicators: a dummy for employment (that is individuals who report working), weekly hours of work, and monthly earnings.

\subsection{Firm Level Variables}

For firm level variables, I rely on two datasets: The Ghana Industrial census, which was conducted in 2003 and the Integrated Business Establishment Survey (IBES) conducted in 2014. Although the survey was conducted in 2014, firms were asked to report their business activities for the year 2013. The IBES covers all business establishments across all sectors in Ghana. I am interested in the industrial sector, hence only establishments in the industry are considered $^{8}$. Using the two data sets, I create a panel of firms in the industrial sector for the years 2003 to 2013. Because this paper's focus is on SMEs, the sample is restricted to small and medium enterprises. Small and medium enterprises are defined as firms that employ between 1 and 30 workers. The firms in the census are classified by 3-digit International Standard Industrial Classification (ISIC) codes. All firms report information on revenue, capital, investments, the number of workers, inputs used for production including fuels bought, electricity purchased, raw materials, and other inputs specific to each firm. The main outcome variables include firms' output, fixed capital, total number of workers, and the number of electricity-intensive firms.

\subsection{Power Outage}

Data on electricity shortages in developing countries is often not available, difficult to request from electricity agencies or is not of high quality when available. To overcome this challenge, I use nighttime lights data from meteorological satellite following an approach introduced by Alam (2013). The US Air Force Defense Meteorological Satellite Program (known as the DMSP-OLS Nighttime Lights Global Composites) compiles this data . ${ }^{9}$ All composites are at a resolution of 30 arc seconds. The National Geophysical Data Center (NGDC) creates the average visible lights composite (AVL) from the observed raw data. Two other composites known as the stable lights (SL) and normalized visible lights (NL) are produced by removing observations with cloud cover, and natural lights such as sunlight and moonlight.
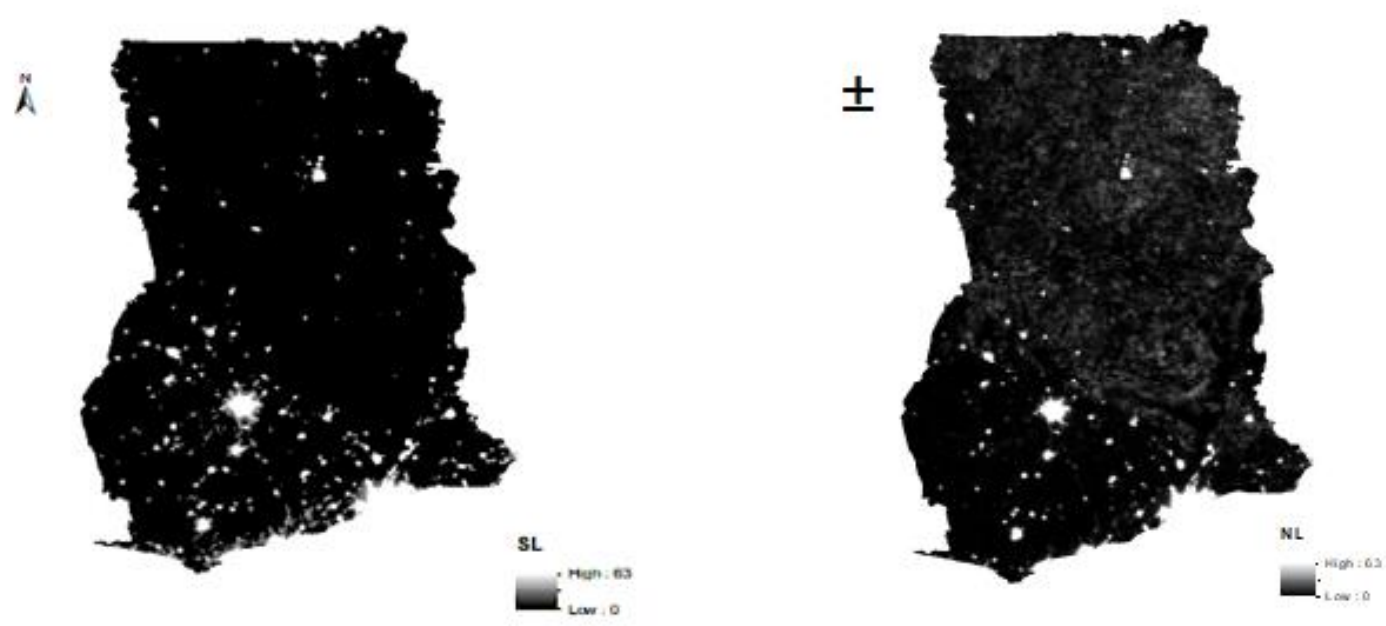

Figure 2. Stable Lights and Normalized Lights

Notes: The map on the left panel is the 2013 Stable Lights (SL) and 2013 Normalized Lights (NL) on the right. Both maps are based on DMSP-OLS nightlights data.

The lights are given digital numbers (DN) ranging from 0 to 63 . Higher values indicate higher luminosity and small

${ }^{8}$ Sectors classified as industry by the Ghana Statistical Service (GSS) include manufacturing, mining and quarrying, construction, electricity and sewerage. Among these sectors, the manufacturing sector is the largest.

${ }^{9}$ http://ngdc.noaa.gov/eog/dmsp/downloadV4composites.html 
values indicate low luminosity. The cleaned stable lights (SL) contain lights from cities, towns, and other sites with persistent lighting. As a result, the data values range from 1-63. The normalized visible lights (NL) on the hand include a percent frequency lights detection term, which normalizes the resulting digital values for variations in the persistence of lighting. For instance, if light is observed only half of the time, the percent frequency will be $0.50 .^{10}$ Figure 2 shows a map of Ghana's stable and normalized lights in 2013. The data is available for the years 1992 to 2013. Using this data, I create a measure of power outages following an approach by Alam (2013).

To create power outages, I use the stable lights composite (SL) and the normalized lights composite (NL) to create nighttime lights variability. That is, the variation in light intensity. Power outages are constructed at the district level for the years of interest. For each year, top-coded observations are removed because the pixels for these observations are saturated. Observations with no stable light pixels are removed because they may be inhabitable areas such as forests. I then construct a measure of variability by obtaining the ratio of SL to NL at each 30 arc second grid point (pixel by pixel). The median of all ratios within the boundaries of a district is then used as measure of power outage for the district. The variability in the brightness of the SL and NL composites is higher for locations with frequent power outages. The resulting values range from 1 to 3 . Outage is measured as follows

$$
\text { outage }_{d t}=\left(\operatorname{med}_{i \in d t}\left(\frac{S L_{i d t}}{N L_{i d t}}\right)\right)
$$

Here, outage $d t$ is the measure of power outage in district $d$ in year $t$, and $\frac{S L_{i d t}}{N L_{i}}$ is the ratio of SL and NL composites at each pixel $i$ in district $d$ in year $t$. A variability of 1 indicates that there is no power outage at the median location of a particular district. An outage value of 2 implies that a district experiences power outages half of the day (12 hours). The average power outage in the sample is approximately 1.4 (Table 1 panel B), which implies that on average, a district in the sample enjoys only 17 hours of electricity supply and 7 hours of outage.

Table 1. Summary Statistics

\begin{tabular}{lcc}
\hline & Mean & SD \\
\hline Panel A: Employment Variables & & 0.177 \\
\hline Indicator for work & 0.690 & 12.1 \\
Weekly hours of work & 40.56 & 3.629 \\
Monthly earnings (GHS) & 8.321 & 3.461 \\
Age & 35.56 & 0.222 \\
Tertiary education & 0.330 & 0.107 \\
Secondary education & 0.111 & 0.142 \\
Primary education & 0.209 & 102.4 \\
Monthly Precipitation & 1131.6 & 0.216 \\
Poverty rate & 0.347 & 2619.8 \\
Population density & 1089.5 & 1782 \\
N & & 2347267.3 \\
\hline Panel B: Firm level & & 36.18 \\
\hline Revenue (GHS) & 76231.65 & 96401.9 \\
No. of Workers & 6.482 & 40036.4 \\
Capital (GHS) & 6303.3 & 340036.2 \\
Electricity (GHS) & 732.0 & 0.102 \\
Inputs (GHS) & 3340.3 & 0.368 \\
Electricity intensity & 0.046 & 7820 \\
Power Outage & 1.353 & \\
N & & \\
\hline
\end{tabular}

Notes: All monetary values are in 2013 Ghana Cedis (GHS). Statistics are calculated using sample weights from surveys.

Since power outages in Ghana sometimes last as long as 24 hours, it is reasonable to assume that the frequency of power outages during the day is similar during the night. Moreover, some of the small and medium enterprises operate from morning throughout the night. Thus, we can safely use the variability in nighttime lights as a proxy measure of outages. Evidence suggests that nighttime light is an accurate measure of electrification (Dugoua, Kennedy, \& Urpelainen, 2018). Besides being an accurate measure of electrification, Chen and Nordhaus (2011) argue that nightlights data is a good proxy for economic statistics.

${ }^{10}$ That is, discounted at $50 \%$. 
Recently, economists have been using nighttime lights as a measure of economic activity and electrification in general (Bleakley \& Lin, 2012; Henderson, Storeygard, \& Weil, 2012; Michalopoulos \& Papaioannou, 2013). Other studies have used nightlights to measure electricity consumption (He, Ma, Liu, \& Zhang, 2014) and the political economy of electricity distribution (Baskaran, Min, \& Uppal, 2015). Additionally, Alam (2013) uses the variability in nightlights as a measure of power outages.

Although nighttime lights have been shown to be a good proxy for some economic indicators by previous papers, it suffers from measurement errors. Some observations are assigned higher digital band numbers to reflect higher brightness. Due to this saturation, the actual variation in brightness overtime may not be accurately estimated. I deal with this problem by removing top-coded pixels.

\subsection{Summary Statistics}

Summary statistics for all variables of interest are reported in Table 1. Panel A summarizes variables in the district panel sample, and panel B summarizes the variables in the firm panel. On average approximately 70 percent report working. The average weekly hours of work is 40 hours. 33 percent have completed tertiary education, and more than 30 percent live below the poverty line. For the firm sample, the average firm employs 6 people and spends 732 GHS on electricity. The average revenue is 76231 GHS (equivalent to $\$ 32404$ ). ${ }^{11}$ These values are not surprising because firms in the sample are small and medium sized firms.

\section{Empirical Strategy}

It can be argued that power outages are random in Ghana's context because they were intermittent and occurred incidentally. ${ }^{12}$ Moreover, in some cases outages are based on a load shedding schedule. Yet, the outages sometimes take place outside the planned schedule. Thus, firms and households do not have control over an outage occurring. In addition to this, districts and communities do not control their own electricity supply (i.e in terms of generation, transmission and distribution). These are determined nationally by three separate government agencies. However, I use a number of measures to address concerns about potential endogeneity transpiring from the outage variable being correlated with other factors. For instance, richer districts or districts growing faster may experience less frequent power outages due to political factors.

First, I show that outages are not correlated with initial district characteristics. This is based on the fact that some initial characteristics of a district may determine whether it will be favored in terms of load shedding for power outages or whether it will experience frequent outages. I regress a number of district variables measured in the year 2000 on outages. The variables include precipitation, fraction of people living in urban areas, fraction of people with primary and secondary education, population density, and poverty rate. Table 1.1 reports these regressions. The results are statistically insignificant suggesting that outages are not correlated with economic characteristics of the districts.

Table 1.1. Correlation between baseline district characteristics and outages

\begin{tabular}{lc}
\hline & Log Outages \\
\hline & \\
Poverty rate & -0.002 \\
& $(0.001)$ \\
Fraction living in urban & -0.039 \\
& $(0.096)$ \\
Fraction with secondary education & -0.012 \\
& $(0.021)$ \\
Fraction with primary education & 0.010 \\
& $(0.019)$ \\
Rainfall & 0.000 \\
& $(0.000)$ \\
Population density & -0.120 \\
& $(0.336)$ \\
\hline
\end{tabular}

Notes: This table reports the coefficients from regressing each district variable on outages. All variables are based on the year 2000 measures. Standard errors in parentheses are clustered at the district level $(* * * \mathrm{p}<0.01, * * \mathrm{p}<0.05, *$ $\mathrm{p}<0.1)$.

11 This amount is based on 2013 exchange rate as at December 2013 (1 USD $=2.3525$ GHS). https://www.exchange-rates.org/Rate/USD/GHS/12-31-2013

${ }^{12}$ Power outages in Ghana are due to various reasons. Refer to Section 2 for a discussion on why outages are frequent in Ghana. 
Secondly, I include district fixed effects, time fixed effects, as well as control for the baseline district covariates. To test for the effects of power outages on employment, I estimate the following equation

$$
y_{d t}=\sigma+\beta \text { Outages }_{d t}+\gamma X_{d t}+\delta_{t}+\mu_{d}+\varepsilon_{d t}
$$

Here, $y_{d t}$ is an outcome for district $d$ in year t, Outages $d t$ is a measure of power outages in a district, $\delta_{t}$ is a time fixed effects, and $\mu_{d}$ is a district fixed effects. Districts that experience higher economic growth may experience more power outages due to an increase in the demand for electricity. Other unobserved factors may be correlated with power outages, and the outcomes of interest. To address this concern, I include a number of district covariates. Included in $X_{d t}$ are district controls for average age, fraction of individuals with primary, secondary and tertiary level education, average monthly precipitation, population density, urban population, and poverty rate (fraction of households living below the poverty line). The district fixed effects control for time-invariant characteristics of the districts and time fixed effects control for district trends that may affect outages overtime. Standard errors are clustered at the district level.

\section{Results}

\subsection{Employment Outcomes}

The main results are reported in Table 2. Column 1 reports results from estimating the effects of power outages on the probability of employment. The estimate suggests that a 10 percent increase in power outages reduces the probability of work by 0.52 percentage points. This translates into a reduction of 7.5 percent in employment. In columns 2, I estimate the effects of outages on monthly earnings. The results show that a 10 percent increase in outages decrease monthly earnings by 3.4 percent. The results in column 3 indicate that outages reduce hours of work significantly. There are several mechanisms through which outages can affect employment. Outages affect employment through a supply and demand for labor channel.

Table 2. Effects of outages on Employment

\begin{tabular}{|c|c|c|c|}
\hline & $\begin{array}{c}(1) \\
\text { Work } \\
\end{array}$ & $\begin{array}{c}(2) \\
\text { Log monthly earnings }\end{array}$ & $\begin{array}{c}\text { (3) } \\
\text { Hours of } \\
\text { work }\end{array}$ \\
\hline Log Outage & $\begin{array}{r}-0.052 * * \\
(0.026)\end{array}$ & $\begin{array}{c}-0.342^{* *} \\
(0.144)\end{array}$ & $\begin{array}{c}-0.277 * * * \\
(0.071)\end{array}$ \\
\hline Observations & 1,759 & 1,668 & 1,757 \\
\hline District Controls & Yes & Yes & Yes \\
\hline Time fixed effects & Yes & Yes & Yes \\
\hline
\end{tabular}

Notes: Work is a dummy equal to 1 if an individual reports working in the past week.

All regressions include district fixed effects. Standard errors in parentheses are clustered at the district level. (*** $\mathrm{p}<0.01, * * \mathrm{p}<0.05, * \mathrm{p}<0.1)$.

On the supply side, power outages may discourage households from engaging in income generating activities that are energy intensive. On the demand side, outages affect industrialization in general, the composition of industry, firm revenues, hours of operation, and labor productivity. Firms respond by reducing wages and decreasing their labor demand. I discuss these mechanisms in detail in the next section.

\subsection{Channels}

In this section, I present a number of channels through which power outages affect employment. I focus on both supply and labor demand and present results from testing these mechanisms.

\subsubsection{Labor Demand}

Power outages affect the productivity of firms. As a result, firms respond by cutting wage, reducing employment, hours and days of operation, or change their production processes. Following standard economic theory, the value of the marginal product of labor is equivalent to the wage. Hence, outages would affect wages through the marginal product of labor. If electricity and labor inputs are complementary, the absence of electricity will reduce the marginal product of labor. Also, the absence of electricity increases the cost of electricity due to the use of alternative energy sources such as generators. We will expect the high cost of electricity coupled with low labor productivity to cause firms to decrease their labor input.

Outages as well decrease firms' output and may reduce the number of firms in an industry due to some firms exiting. 
Moreover, firms may change their production processes from electricity intensive to less electricity intensive ones when outages are severe. However, if electricity intensive production processes enhance productivity, a change from high intensity to low intensity will decrease firm's productivity. This in turn will affect a firm's labor demand because a firm's electricity intensity is positively correlated with labor productivity (Abeberese, 2017). The following hypotheses can be tested:

I. Firms reduce wages: If outages decrease labor productivity, firms will reduce wages.

II. Firms decrease employment: Frequent power outages imply low output and high cost of production. Hence, if labor productivity is low but the price of labor input is high (wage), firms will decrease the number of workers.

III. Output and Composition of Industry: Outages may decrease output and drive firms to change their production processes from electricity intensive to less electricity intensive ones.

\subsubsection{Labor Supply}

On the supply side, we would expect supply of labor to decrease if power outages reduce opportunities for household members to engage in income generating activities. Income generating activities come in the form of self-employment and wage employment. Additionally, severe outages will cause households to spend more time on home production, which implies that less time will be available for outside work. Based on this, the following three hypotheses can be tested:

I. Decreased prevalence of SMEs (self-employment) and wage employment: Outages may discourage individuals from operating or investing in SMEs due to increased production costs. Moreover, individuals may have fewer employment opportunities available if firms cut wages and fire workers.

II. Time Use: Households may spend more time on home production and other activities, implying that less time will be available for them to supply their labor to markets.

\subsubsection{Firms' Response: Wages and Employment}

Here, I test hypotheses I and II under section 5.2.1. When electricity is not available, some firms do not operate, work for fewer hours or shut down for the day. This implies that these firms may experience losses and workers will have reduced hours or days of work. Low marginal productivity of labor will cause firms to reduce wages. I rely on a sample of informal firms to examine the effect of outages on wages and total number of workers employed by firms. I estimate the following,

$$
y_{i d t}=\sigma+\text { BOutages }_{d t}+\gamma_{d t}+\lambda_{j t}+\mu_{i}+\varepsilon_{i d t}
$$

Here, $y_{i d t}$ is an outcome for firm $i$ in district $d$ in year $t$. The specification includes a firm fixed-effects $\left(\mu_{i}\right)$ to account for firm in-variant characteristics, and district-year fixed effects for unobserved factors that affect firms within a district overtime. I include an industry-year fixed effects $\left(\gamma_{d t}\right)$ to account for the fact that there may be differences in the business environment faced by firms, and industries may experience outages differently. This ensures that differential industry trends in the outcomes are accounted for. Included are district controls such as average precipitation. Standard errors are clustered at the firm level.

These results are reported in table 3 . I find that power outages significantly reduce wages and employment. The number of workers decreases by about 0.7 percent for a 10 percent increase in outages and wages by 1.8 percent. The negative effect is an indication that firms' decrease employment by reducing labor demand and lower wages when outages are severe. The results are consistent with Abeberese et al. (2017) who find similar results. These findings are not surprising because a large proportion of firms in Ghana are in the informal sector. As a result, the absence of formal contracts, and wages being determined by various factors are plausible. The firms can lay-off workers when unfavorable conditions such as revenue losses occur.

Anecdotal evidence shows that majority of the firms in the industrial sector laid-off workers due to severe power outages. Over 300 workers were scheduled to be laid-off in a city considered to be one of the major industrial hubs in Ghana. ${ }^{13}$ Some firms fail to register their businesses in order to avoid labor unions and contractual agreements. According to Akorsu (2013), the labor laws in Ghana are not strictly imposed on firms in the informal sector. Employment contracts are non-existent and employees are not unionized. In addition to anecdotal evidence from the media, quantitative evidence suggests that manufacturing firms in Ghana respond to outages by decreasing wages and

13 "Over 300 workers in Tema to lose jobs due to 'dumsor' (power outages)". News article from Modern Ghana and Citi Fm. "Dumsor" means "on and off" in the Akan language.

https://www.modernghana.com/news/707118/return-of-dumsor-over-300-workers-in-tema-to-lose-jobs.html 
the number of workers they hire ((Abeberese et al., 2017) .

Table 3. Effects of outages on number of workers and wages

\begin{tabular}{lcc}
\hline & $(1)$ & $(2)$ \\
& $\log$ (workers) & Log (earnings/worker) \\
\hline \multirow{2}{*}{ Log Outage } & $-0.066^{* * * *}$ & $-0.187^{* * *}$ \\
& $(0.025)$ & $(0.085)$ \\
Observations & 7,816 & 4,397 \\
District-time fixed effects & Yes & Yes \\
\hline
\end{tabular}

Notes: All regressions include district level controls and industry-year fixed effects.

Standard errors in parentheses are clustered at the firm level $(* * * \mathrm{p}<0.01, * * \mathrm{p}<0.05, * \mathrm{p}<0.1)$.

\subsubsection{Industrial Growth and the Composition of Industry}

I next investigate whether outages affect industrial growth and the composition of firms in the industry, that is, high electricity-intensive and low electricity-intensive firms. Power outages decrease firms' output and some firms may exit. The introduction of electricity in a particular area or district stimulates the growth of existing firms and the emergence of new ones. Rud (2012) finds that in India, the introduction of electricity in rural areas led to an increase in industrialization. Manufacturing output increased, as well as increases in the number of firms in areas that received electricity. However, unreliable electricity supply will affect industrial growth negatively.

Additionally, outages affect the composition of industry. The intuition behind this mechanism is that severe outages increase the cost of operation for firms operating electricity-intensive production processes as a result of investment in generators. The high cost of operation may cause firms to operate less electricity-intensive processes that may be more productive. Using data from the firm survey, I rely on a number of indicators of industrial growth following Rud (2012). The indictors include firms' output, fixed capital, and the total number of firms in a district. Similar to the regressions in equation (2), I examine the effects of outages on these outcomes. Industrial output is defined as the total output of firms in a district, number of firms refers to the total number of firms in a district, and fixed capital is the total capital of all firms in a particular district.

For the composition of industry, I use the number of electricity-intensive firms as an outcome variable. Electricity-intensity is defined as the ratio of electricity purchased to revenue. Firms whose electricity revenue share exceeds the median electricity usage are classified as electricity-intensive firms. The results are presented in Table 4 . The results indicate that outages affect industrial growth negatively. Industrial output and the total number of firms in a district decrease significantly as outages increase. However, there is no significant impact on fixed capital. Column 4 shows that outages reduce the number of electricity-intensive firms in a district by 1.9 percent. Recent evidence suggests that manufacturing firms in Ghana change their production processes to less electricity-intensive ones and stop the production of electricity-intensive products when outages are severe (Abeberese et al., 2017). This has implications for the productivity growth of firms and employment creation.

Table 4. Effect of power outages on industrial growth

\begin{tabular}{lcccc}
\hline & $\begin{array}{c}(1) \\
\text { Industrial } \\
\text { output }\end{array}$ & $\begin{array}{c}(2) \\
\text { Fixed } \\
\text { capital }\end{array}$ & $\begin{array}{c}(3) \\
\text { Number of } \\
\text { firms }\end{array}$ & $\begin{array}{c}(4) \\
\text { Number of } \\
\text { energy-intensive firms }\end{array}$ \\
\hline Log Outage & $-0.512^{*}$ & -0.372 & $-0.169^{* * *}$ & $-0.193^{* *}$ \\
& $(0.229)$ & $(0.421)$ & $(0.047)$ & $(0.083)$ \\
Observations & 1,155 & 836 & 1,156 & 1,149 \\
$\begin{array}{l}\text { District controls } \\
\begin{array}{l}\text { District-time } \\
\text { fixed effects }\end{array}\end{array}$ & Yes & Yes & Yes & Yes \\
\hline
\end{tabular}

Notes: Capital is defined as the total fixed capital of all firms in a district. All variables are in logs.

Standard errors in parentheses are clustered at the district level. ( $* * * \mathrm{p}<0.01, * * \mathrm{p}<0.05, * \mathrm{p}<0.1)$.

All regressions include district fixed effects.

\subsubsection{Prevalence of Small and Medium Enterprises (SMEs)}

Here, I investigate whether power outages reduce employment through a decreased prevalence of small and medium 
enterprises and opportunities for wage employment. Since households engage in income generating activities in the form of small and medium enterprises, the absence of reliable electricity supply implies a reduction in these activities. Moreover, as firms reduce wages and the number of workers they hire, households are left with fewer employment opportunities.

I rely on the district panel data from the household survey to estimate the effects of outages on the prevalence of SMEs. The prevalence of SMEs is defined as the likelihood to operate an enterprise or engage in self-employment activities. Column 2 in Table 5 reports the effects of outages on the probability of self-employment. The results show that a 10 percent increase in outages (an additional hour of outage) decreases the probability of self-employment by 0.39 percentage points. Additionally, I explore whether individuals are shifting from self-employment to wage employment as a result of outages. I find that wage employment decreases by 0.24 percentage points when outages increase by 10 percent. The results show that the negative employment effect is due to reductions in both wage employment and self-employment.

Table 5. Effects of outages on wage and Self-employment

\begin{tabular}{lcc}
\hline & $(1)$ & $(2)$ \\
& Self-employment & Wage-employment \\
\hline Log Outage & $-0.039^{* *}$ & $-0.024^{* *}$ \\
& $(0.016)$ & $(0.012)$
\end{tabular}

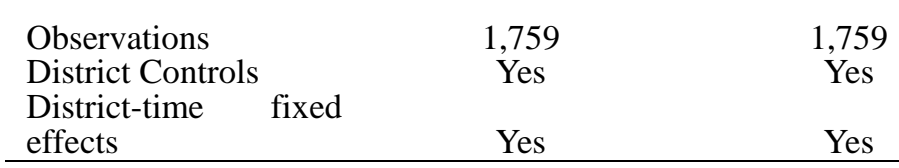

Notes: Self-employment and wage employment are dummies equal to 1 if an individual reports being self-employed or a wage worker. Standard errors in parentheses are clustered at the district level. $(* * * p<0.01, * * p<0.05, * p<0.1)$.

All regressions include district fixed effects.

Table 6. Robustness check - Effects of on Employment, using available electricity

\begin{tabular}{|c|c|c|c|c|c|}
\hline & Work & Hours worked (per week) & $\begin{array}{c}\text { (3) } \\
\text { Log } \\
\text { monthly } \\
\text { earnings }\end{array}$ & Self-employment & Wage employment \\
\hline Log Average lights & $\begin{array}{l}0.005^{*} \\
(0.003)\end{array}$ & $\begin{array}{c}0.039 * * * \\
(0.008)\end{array}$ & $\begin{array}{c}0.072 * * * * \\
(0.016)\end{array}$ & $\begin{array}{c}0.008 * * * \\
(0.001)\end{array}$ & $\begin{array}{c}0.018 * * * \\
(0.002)\end{array}$ \\
\hline Observations & 1,778 & 1,776 & 1,685 & 1,742 & 1,742 \\
\hline District Controls & Yes & Yes & Yes & Yes & Yes \\
\hline District-time fixed effects & Yes & Yes & Yes & Yes & Yes \\
\hline
\end{tabular}

Notes: Work is a dummy equal to 1 if an individual reports working in the past week. Self-employment and wage employment are dummies equal to 1 if an individual reports being self-employed or a wage worker. Standard errors in parentheses are clustered at the district level. $(* * * \mathrm{p}<0.01, * * \mathrm{p}<0.05, * \mathrm{p}<0.1)$. All regressions include district fixed effects.

\subsubsection{Power Outages and Time Use}

In addition to the potential mechanisms discussed, it is possible that individuals quit work or reduce their hours of work themselves instead of firms' laying-off workers. This is likely to happen if outages affect households' time use. One of the major arguments for electrification is that electricity serves as a technology that reduces time allocated to home production and as a result households are able to engage in work outside the home (labor supply). However, when the electricity available is unreliable, they might end up spending more time in home production. Meaning that, less time will be available for market work.

For instance, households may switch to the use of wood for cooking instead of lighting when electricity is unavailable. It will be ideal to investigate how outages affect the households' allocation of time but due to data limitations, I am unable to test this claim. There is no data on households' time use. Though power outages may affect time use negatively, the effect maybe larger or be driven by individuals who are casual workers and part-time workers. The 
reason being that these workers spend less time on market activities, hence, the advent of severe outages forces them to allocate more time towards home production. This is particular true for women who engage in casual work.

\subsection{Robustness Check}

I discuss the sensitivity of the main results in this section. In Table 5 power outages are transformed into the amount of time that lights are available. Hence, instead of power outages, the main variable of interest is electricity. We expect the availability of lights to have positive effects on employment. As shown in column 1, the availability of light increases the probability of employment. Columns 2 and 3 report the impacts on hours worked and monthly earnings. The results are significant and positive.

\section{Conclusion}

This paper estimates the impacts of unreliable electricity supply on employment. I find that a 10 percent increase in power outages reduces the likelihood of employment by 7.5 percent and monthly earnings by 3.4 percent. Further evidence from mechanisms underlining this effect indicates that power outages reduce industrial output, number of firms, and the composition of industry. Moreover, as outages become frequent, households are less likely to operate small and medium enterprises.

This study complements the literature on electrification and infrastructure in general by highlighting the importance of infrastructure quality (intensive margin). Though electrification rates have increased over the past decade, the quality of service provision is rather poor. Unreliable electricity hurt small and medium businesses in developing countries and most importantly, employment. Because firms are unable to operate efficiently, expand, and hire more labor. The fact that electricity shortages affect income and employment has some welfare implications. Additionally, given that Small and Medium Enterprises (SMEs) are crucial for job creation in developing countries, investment in reliable and efficient electricity infrastructure is imperative.

Finally, future research can examine how reliable electricity supply affect time use at the household level and entry and exit of small and medium enterprises at the firm level.

\section{Acknowledgements}

Thanks to Nori Tarui, Inessa Love, Teresa Molina, and Ruben Juarez. All errors are mine.

\section{References}

Abeberese, A. B. (2017). Electricity cost and firm performance: Evidence from India. Review of Economics and Statistics, 99(5), 839-852. https://doi.org/10.1162/REST_a_00641

Abeberese, A. B., Ackah, C., \& Asuming, P. (2017). Productivity losses and firm responses to electricity shortages: Evidence from Ghana.

Adofo, J. O., Tarui, N., \& Tanaka, T. (2019). The Local Economic Effects of Natural Resources : Evidence from Ghana.

Akorsu, A. D. (2013). Labour standards application in the informal economy of ghana: the patterns and pressures. Ekonomski Anali/Economic Annals, 58(196). https://doi.org/10.2298/EKA1396157A

Alam, M. (2013). Coping with blackouts: Power outages and firm choices. Department of Economics, Yale University.

Alby, P., Dethier, J. J., \& Straub, S. (2013). Firms operating under electricity constraints in developing countries. The World Bank Economic Review, 27(1), 109-132. https://doi.org/10.1093/wber/lhs018

Andersen, T. B., \& Dalgaard, C. J. (2013). Power outages and economic growth in Africa. Energy Economics, 38(C), 19-23. https://doi.org/10.1016/j.eneco.2013.02.016

Baisa, B., Davis, L. W., Salant, S. W., \& Wilcox, W. (2010). The welfare costs of unreliable water service. Journal of Development Economics, 92(1), 1-12. https://doi.org/10.1016/j.jdeveco.2008.09.010

Barron, M., \& Torero, M. (2017). Household electrification and indoor air pollution. Journal of Environmental Economics and Management, 86, 81-92. https://doi.org/10.1016/j.jeem.2017.07.007

Baskaran, T., Min, B., \& Uppal, Y. (2015). Election cycles and electricity provision: Evidence from a quasi-experiment with Indian special elections. Journal of Public Economics, 126(C), 64-73. https://doi.org/10.1016/j.jpubeco.2015.03.011

Bleakley, H., \& Lin, J. (2012). Portage and path dependence.(Report). Quarterly Journal of Economics, 127(2), 587. https://doi.org/10.1093/qje/qjs011

Chakravorty, U., Pelli, M., \& Ural Marchand, B. (2014). Does the quality of electricity matter? Evidence from rural India. Journal of Economic Behavior and Organization, 107(PA), 228-247.

https://doi.org/10.1016/j.jebo.2014.04.011 
Chen, X., \& Nordhaus, W. D. (2011). Using luminosity data as a proxy for economic statistics. Proceedings of the National Academy of Sciences of the United States of America, 108(21), 8589. https://doi.org/10.1073/pnas.1017031108

Cole, M. A., Elliott, R. J. R., Occhiali, G., \& Strobl, E. (2018). Power outages and firm performance in Sub-Saharan Africa. Journal of Development Economics, 134, 150-159. https://doi.org/10.1016/j.jdeveco.2018.05.003

Collard-Wexler, A., \& O'Connell, S. (2016). How Do Electricity Shortages Affect Industry? Evidence from India. The American Economic Review, 106(3), 587-624. https://doi.org/10.1257/aer.20140389

Dinkelman, T. (2011). The effects of rural electrification on employment: new evidence from South Africa.(Report)(Author abstract). American Economic Review, 101(7), 3078-3108. https://doi.org/10.1257/aer.101.7.3078

Donaldson, D. (2018). Railroads of the Raj: Estimating the Impact of Transportation Infrastructure.(Author abstract). American Economic Review, 108(4-5), 899-934. https://doi.org/10.1257/aer.20101199

Dugoua, E., Kennedy, R., \& Urpelainen, J. (2018). Satellite data for the social sciences: measuring rural electrification with night-time lights. International Journal of Remote Sensing, 39(9), 2690-2701. https://doi.org/10.1080/01431161.2017.1420936

Fisher-Vanden, K., Mansur, E. T., \& Wang, Q. (2015). Electricity shortages and firm productivity: Evidence from China's industrial firms. Journal of Development Economics, 114(C), 172-188. https://doi.org/10.1016/j.jdeveco.2015.01.002

Grimm, M., Sparrow, R., \& Tasciotti, L. (2015). Does Electrification Spur the Fertility Transition? Evidence From Indonesia. Demography, 52(5), 1773-1796. https://doi.org/10.1007/s13524-015-0420-3

Grogan, L. (2018). Time use impacts of rural electrification: Longitudinal evidence from Guatemala. Journal of Development Economics, 135, 304-317. https://doi.org/10.1016/j.jdeveco.2018.03.005

Grogan, L., \& Sadanand, A. (2013). Rural Electrification and Employment in Poor Countries: Evidence from Nicaragua. World Development, 43(C), 252-265. https://doi.org/10.1016/j.worlddev.2012.09.002

Gronau, R. (1977). Leisure, Home Production, and Work--the Theory of the Allocation of Time Revisited. Journal of Political Economy, 85(6), 1099-1123. https://doi.org/10.1086/260629

Hardy, M., \& Mccasland, J. L. (2019). Lights off, lights on: The effects of electricity shortages on small firms. World Bank Policy Research Working Paper(9093). https://doi.org/10.1596/1813-9450-9093

He, C., Ma, Q., Liu, Z., \& Zhang, Q. (2014). Modeling the spatiotemporal dynamics of electric power consumption in Mainland China using saturation-corrected DMSP/OLS nighttime stable light data. International Journal of Digital Earth, 7(12), 993-1014. https://doi.org/10.1080/17538947.2013.822026

Henderson, J. V., Storeygard, A., \& Weil, D. N. (2012). Measuring economic growth from outer space.(Author abstract). American Economic Review, 102(2), 994-1028. https://doi.org/10.1257/aer.102.2.994

Kanagawa, M., \& Nakata, T. (2008). Assessment of access to electricity and the socio-economic impacts in rural areas of developing countries. Energy Policy, 36(6), 2016-2029. https://doi.org/10.1016/j.enpol.2008.01.041

Lipscomb, M. (2013). Development effects of electrification : evidence from the topographic placement of hydropower plants in Brazil. American economic journal : a journal of the American Economic Association, 5(2), 200-231. https://doi.org/10.1257/app.5.2.200

Michalopoulos, S., \& Papaioannou, E. (2013). Pre-Colonial Ethnic Institutions and Contemporary African Development. Econometrica, 81(1), 113-152. https://doi.org/10.3982/ECTA9613

Modern Ghana. (2019, November 15). Retrieved November 15, 2009, from https://www.modernghana.com/news/707118/return-of-dumsor-over-300-workers-in-tema-to-lose-jobs.html

Morimoto, R., \& Hope, C. (2004). The impact of electricity supply on economic growth in Sri Lanka. Energy Economics, 26(1), 77-85. https://doi.org/10.1016/S0140-9883(03)00034-3

Peters, J., \& Vance, C. (2011). Rural electrification and fertility-evidence from Côte d'Ivoire. The Journal of Development Studies, 47(5), 753-766. https://doi.org/10.1080/00220388.2010.527954

Rud, J. P. (2012). Electricity provision and industrial development: Evidence from India. Journal of Development Economics, 97(2), 352-367. https://doi.org/10.1016/j.jdeveco.2011.06.010

van de Walle, D., Ravallion, M., Mendiratta, V., \& Koolwal, G. (2017). Long-term Gains from Electrification in Rural India. The World Bank Economic Review, 31(2), 385-411. 
World Bank Enterprise Survey, Enterprise Surveys. Retrieved from http://www.enterprisesurveys.org

\section{Copyrights}

Copyright for this article is retained by the author(s), with first publication rights granted to the journal.

This is an open-access article distributed under the terms and conditions of the Creative Commons Attribution license which permits unrestricted use, distribution, and reproduction in any medium, provided the original work is properly cited. 